\title{
TEST DATA ANALYSIS OF A SPRAY BAR ZERO-GRAVITY LIQUID HYDROGEN VENT SYSTEM FOR UPPER STAGES
}

\author{
A. Hedayat ${ }^{\mathrm{a}}$, J. W. Bailey ${ }^{\mathrm{b}}$, L. J. Hastings ${ }^{\mathrm{c}}$, and R. H. Flachbart ${ }^{\mathrm{a}}$ \\ aNASA Marshall Space Flight Center \\ Marshall Space Flight Center, Alabama 35812, USA \\ ${ }^{b}$ Sverdrup Technology, Inc. \\ Marshall Space Flight Center Group \\ Huntsville, Alabama 35806, USA \\ 'Alpha Technology, Inc. \\ Huntsville, Alabama 35806, USA
}

\begin{abstract}
To support development of a zero-gravity pressure control capability for liquid hydrogen $\left(\mathrm{LH}_{2}\right)$, a series of thermodynamic venting system (TVS) tests was conducted in 1996 and 1998 using the Marshall Space Flight Center (MSFC) multipurpose hydrogen test bed (MHTB). These tests were performed with ambient heat leaks $\approx 20$ and $50 \mathrm{~W}$ for tank fill levels of $90 \%, 50 \%$, and $25 \%$. TVS performance testing revealed that the spray bar was highly effective in providing tank pressure control within a 7-kPa band (131-138 kPa), and complete destratification of the liquid and the ullage was achieved with all test conditions. Seven of the MHTB tests were correlated with the TVS performance analytical model. The tests were selected to encompass the range of tank fill levels, ambient heat leaks, operational modes, and ullage pressurants. The TVS model predicted ullage pressure and temperature and bulk liquid saturation pressure and temperature obtained from the TVS model were compared with the test data. During extended self-pressurization periods, following tank lockup, the model predicted faster pressure rise rates than were measured. However, once the system entered the cyclic mixing/venting operational mode, the modeled and measured data were quite similar.
\end{abstract}

\section{INTRODUCTION}

Maintaining propellant tank pressure control while minimizing propellant boiloff loss is a significant challenge associated with the storage of cryogens in the near-zero-gravity 
environment of space. Traditionally, auxiliary thrusters are used to settle the propellants in order to accomplish tank venting. However, such systems incur weight penalties (associated with the propellant and hardware required to perform the settling burns) that increase with the number of settling sequences required during the mission. In addition, tank venting/resettling may become necessary at inopportune moments in a mission timeline, thereby increasing mission complexity. The TVS concept, which enables tank pressure control through venting without resettling, is presented in the following section.

\section{THERMODYNAMIC VENTING SYSTEM CONCEPT}

Major components of the TVS design, shown in FIG 1, consist of a recirculation pump, Joule-Thomson ( $\mathrm{J}-\mathrm{T}$ ) expansion/shutoff valve, and a parallel flow concentric tube heat exchanger/spray bar apparatus. The pump extracts propellant from the tank and flows it through the heat exchanger/spray bar apparatus. The fluid reenters the tank through orifices in the spray bar that expel the fluid radially into the tank, resulting in propellant destratification and ullage condensation. When pressure control within the tank cannot be maintained through mixing alone (bulk liquid is saturated at the ullage pressure), a small amount of fluid extracted from the recirculation flow is passed through the J-T valve where it is expanded to a lower pressure and temperature. The subcooled liquid is then passed through the heat exchanger, which extracts heat from the recirculation flow, and subsequently vented to the environment. If ullage instead of liquid enters the recirculation line, vapor is vented through the J-T valve and ullage depressurization occurs much as it would in a normal gravity environment. Details of the TVS hardware development effort are provided by Lak and Wood [1].

\section{THERMODYNAMIC VENTING SYSTEM TEST SETUP}

The MHTB aluminum tank is cylindrical with both a height and diameter of $3.05 \mathrm{~m}$, and 2:1 elliptical domes. The MHTB insulation concept consists of a foam/multilayer insulation (MLI) combination. The foam element enables the use of a payload bay-type gaseous nitrogen purge during ground-hold periods. The variable density 45-layer, double-aluminized DuPont ${ }^{\circledR}$ Mylar ${ }^{\circledR}$ MLI provides thermal radiation protection during the simulation of

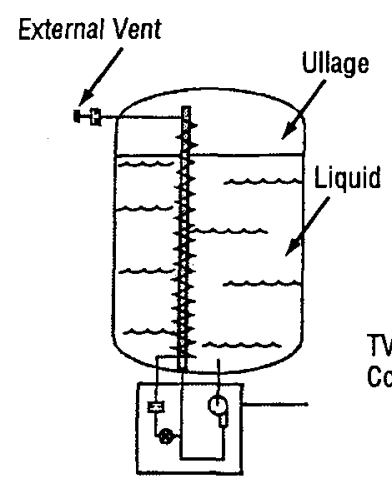

Zero-Gravity TVS Installed in Tank

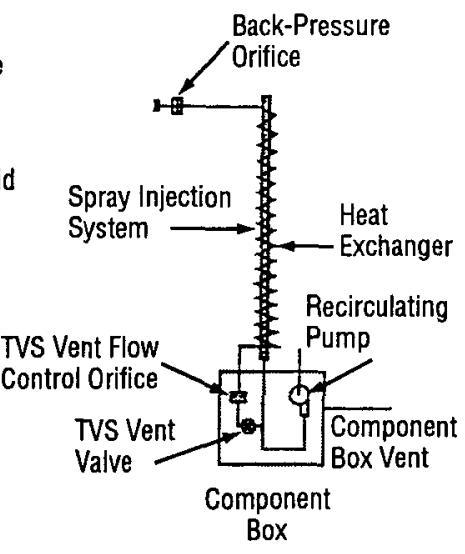

Zero-Gravity TVS Hardware

FIGURE 1. TVS hardware configuration. 
on-orbit vacuum conditions. Detailed descriptions of the MHTB and the insulation system are provided by Martin and Hastings [2]. The MHTB tank is enclosed within an environmental shroud, which simulates a ground-hold conditioning purge similar to that in a payload bay, and enables the imposition of uniform temperatures (ranging from 80 to $320 \mathrm{~K}$ ) on the MLI external surfaces.

Testing was performed at the MSFC east test area thermal vacuum facility, test stand 300. The facility systems, in combination with the MHTB's shroud, enabled simulation of orbital environmental conditions. During the TVS testing, the chamber maintained vacuum levels in a low $10^{-6}$ torr level with the cold walls operating, and $<10^{-5}$ torr without the cold walls.

\section{TEST PROCEDURES}

Boiloff testing was conducted to determine the ambient heat leak into the MHTB tank and to set up consistent baseline conditions prior to each of the TVS tests. The first TVS test series was conducted with the vacuum chamber liquid nitrogen $\left(\mathrm{LN}_{2}\right)$ cold walls operating to produce a minimum heat leak condition of 19-20 W. The second series was conducted without the $\mathrm{LN}_{2}$ cold walls, thereby providing a higher ambient heat leak condition (51-54 W) and reducing test costs. Detailed descriptions of the boiloff tests and procedures are reported by Flachbart et al. [3].

After the heat leak testing was completed for each tank fill level, the tank was locked up and allowed to self-pressurize until the ullage pressure attained the maximum tank pressure set point of $138 \mathrm{kPa}$. Upon reaching this pressure, the recirculation pump was activated, and mixing continued until the ulllage pressure reached the minimum set point (131 kPa). After the pump was turned off at the minimum set point, the tank was allowed to self-pressurize and the cycle began again. This automated operation cycle, with a control band of $\pm 3.45 \mathrm{kPa}$, continued until the $\mathrm{LH}_{2}$ saturation condition attained the lower set point. The J-T vent valve was then opened and the spray bar heat exchanger was utilized to extract thermal energy from the bulk liquid. Thereafter, the J-T valve/spray bar heat exchanger was used each time the pump cycled on.

\section{MODEL OVERVIEW}

A transient one-dimensional analytical model of the TVS was formulated to characterize the TVS performance within the MHTB $\mathrm{LH}_{2}$ tank. The TVS performance formulation is comprised of four combined thermal/fluid models - the heat exchanger, spray manifold and injector tubes, recirculation pump, and tank. The heat exchanger model calculates the quality and two-phase pressure loss at the vent exit. The spray manifold and injection tube model determines the pressure drops within the manifold and tubes along with the spray flow rates and velocities leaving the injection orifices. The recirculation pump model calculates the pump head increase from the pump speed and the head coefficient curve provided by the pump manufacturer. The tank model is a lumped model consisting of four control volumesthe ullage, tank wall, tank wall liquid, and bulk liquid. The ullage is modeled to contain gaseous hydrogen $\left(\mathrm{GH}_{2}\right)$ and/or gaseous helium $(\mathrm{GHe})$. Since the major thrust of the current effort has been to correlate this analytical model/code with the MHTB test data, the TVS analytical model is not provided here. A detailed description of the TVS analytical model is given by Nguyen [4]. 


\section{RESULTS AND DISCUSSIONS}

The TVS testing was conducted in 1996 and 1998; seven tests were modeled for comparison with the TVS performance code. The tests were selected to encompass the range of tank fill levels, ambient heat leaks, operational modes, and ullage pressurants. The model is in good agreement with the test data in the early stages of self-pressurization after tank lockup; however, the analytical pressure begins to deviate and rises more rapidly than the measured values. It is believed the analytical modeling, which assumes that the liquid and ullage are each represented by a single node, did not accurately simulate the complex energy exchange that actually occurred at the liquid-vapor interface. Therefore, the analytical pressure rise rate after tank lockup is conservative relative to the measured data and the modeled mixing cycles begun earlier.

With mixing, the stratification effects are minimized and the energy exchange across the liquid surface is more predictable during the relatively short self-pressurization periods between mixing cycles. Therefore, once the mixing and pressure rise cycles began, the analytical and measured data closely matched. However, it was noted that the measured pressure rise rates were slightly steeper than analytically modeled, whereas the pressure reduction rates were practically identical. Correlations for the bulk liquid saturation pressure and temperature indicated relatively good agreement for the entire range of conditions tested. A summary of test segments compared with the TVS performance code is shown in TABLE 1.

Detailed model predictions and comparisons for test segments P263968G, P263981D, and P263981X are discussed in the following sections.

\section{Test Segment P263968G — Low Heat Leak, Mixing and Venting Mode, 90\% Fill Level}

Correlations for the venting and mixing operation were performed using test segment P263968G, with a 90\% fill level and 20.2-W tank heat leak. The ullage pressure prediction by the model is in good agreement with the test data as depicted in FIG 2 . The model ullage pressure predictions are within the prescribed control interval of $131-138 \mathrm{kPa}$. The data comparison indicates that, initially, the analytical model tracks the measured data very well; however, the model calculates the cycling time to be slower than that of test data. The calculated and measured cycling times are 1.58 and $1.06 \mathrm{hr}$, respectively. The calculated and measured ullage temperatures are shown in FIG 3. The predicted ullage temperature

TABLE 1. TVS Analytical Correlation Cases

\begin{tabular}{lcclllcc}
\hline & $\begin{array}{c}\text { Fill } \\
\text { Level } \\
(\%)\end{array}$ & $\begin{array}{c}\text { Heat } \\
\text { Leak } \\
\text { (W) }\end{array}$ & $\begin{array}{l}\text { Year, Test } \\
\text { Segment No. }\end{array}$ & Operation Mode & $\begin{array}{c}\text { Pressure } \\
\text { Rise } \\
\text { (Model/Test) }\end{array}$ & $\begin{array}{c}\text { Cycle } \\
\text { Rate } \\
\text { Error } \\
(\%)\end{array}$ \\
\hline $\mathrm{GH}_{2}$ & 90 & 54.1 & $1998, \mathrm{P} 263981 \mathrm{D}$ & Tank lockup/mixing & 2 & 4 \\
$\mathrm{GH}_{2}$ & 90 & 20.2 & $1996, \mathrm{P} 263968 \mathrm{G}$ & Mixing/venting & NA & 33 \\
$\mathrm{GH}_{2}$ & 90 & 20.2 & $1996, \mathrm{P} 263968 \mathrm{E} \& \mathrm{~F}$ & Tank lockup/mixing & 2 & 11 \\
$\mathrm{GH}_{2}$ & 50 & 51.0 & $1998, \mathrm{P} 263981 \mathrm{~T}$ & Tank lockup/mixing/venting & 5 & 14 w/o venting \\
& & & & & & 0 w/venting \\
$\mathrm{GH}_{2} \& \mathrm{GHe}$ & 50 & 51.0 & 1998, P263981X & Mixing/venting & NA & NA \\
$\mathrm{GH}_{2}$ & 50 & 18.7 & 1996, P263968K & Mixing/venting & NA & 28 \\
$\mathrm{GH}_{2}$ & 25 & 18.8 & 1996, P263968L & Mixing/venting & NA & 26 \\
\hline
\end{tabular}




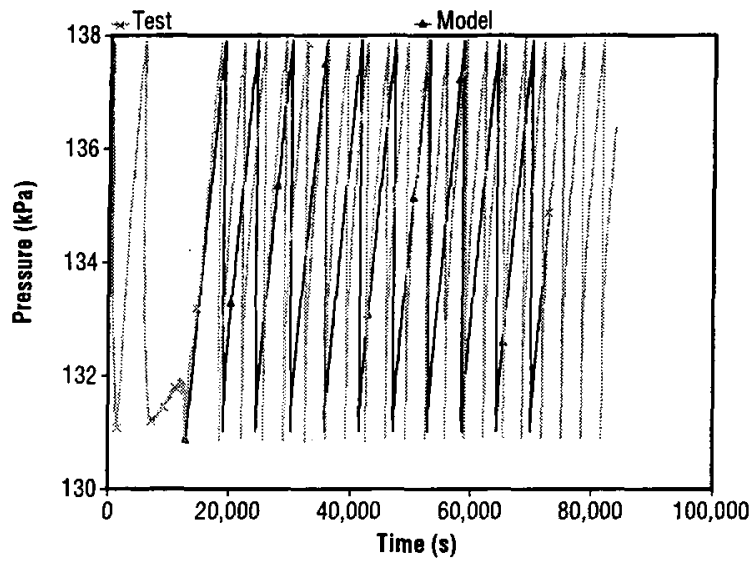

FIGURE 2. Ullage pressure, test P263968G.

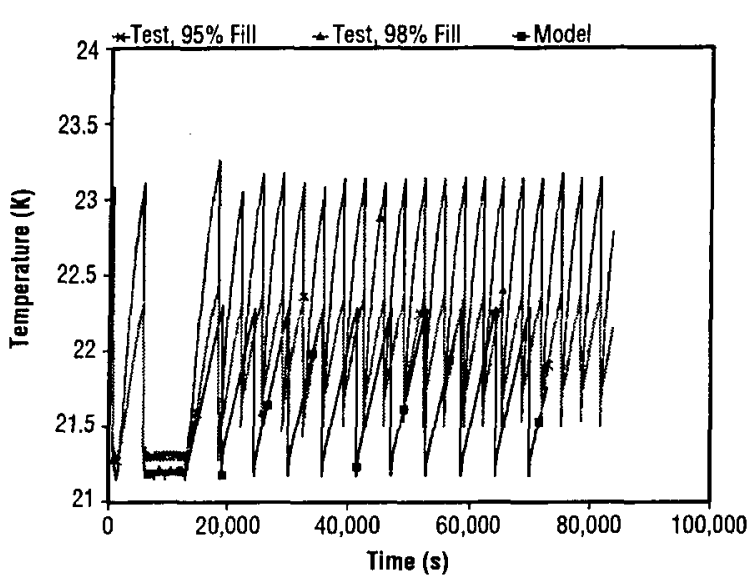

FIGURE 3. Ullage temperature, test P263968G.

is $21.2-22.3 \mathrm{~K}$, which is within the measured ullage temperatures (21.2-23.1 K). FIGS 4 and 5 show good agreement between the predicted and measured bulk liquid saturation pressure and temperature values.

Test Segment P263981D - High Heat Leak, Self-Pressurization and Mixing Mode, 90\% Fill Level

Model correlations with test data for self-pressurization and venting with a $90 \%$ fill level and a 54.1-W heat leak were performed. As illustrated in FIG 6, tank lockup occurred at 10,380 s and self-pressurization proceeded until the mixing cycles began and continued throughout the remainder of the test segment without venting. The model is in good agreement with the test data in the early stages of self-pressurization; however, the analytical pressure data begins to deviate after $\approx 14,500 \mathrm{~s}$ and rises more rapidly than the measured values. A similar comparison occurred with the low heat leak test series. The computed and measured ullage pressures reached the upper pressure limit of $137.9 \mathrm{kPa}$ after about $20,000 \mathrm{~s}$ and $30,000 \mathrm{~s}$, respectively. However, once the mixing cycles began, both the pressure rise and reduction rates correlated very well. The deviation of ullage pressure prediction during the tank lockup could be attributed to stratification effects that are not addressed by the analytical model. FIG 7 represents comparison between calculated and measured ullage

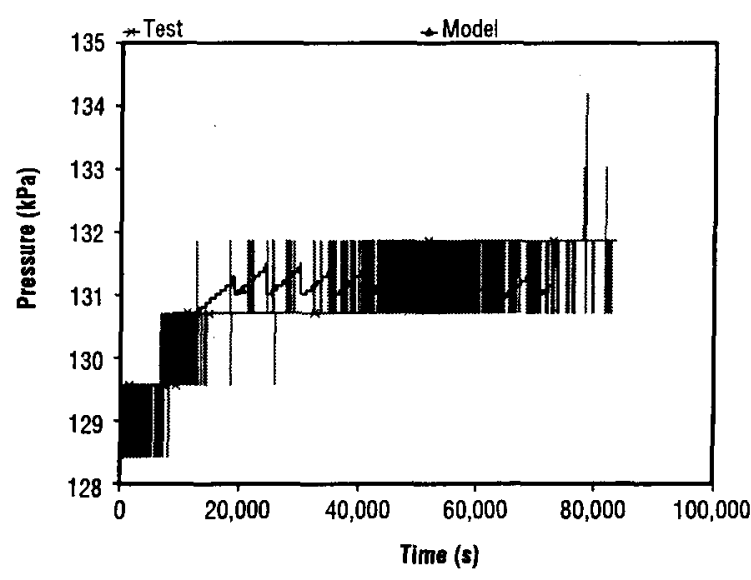

FIGURE 4. Bulk liquid saturation pressure, test P263968G.

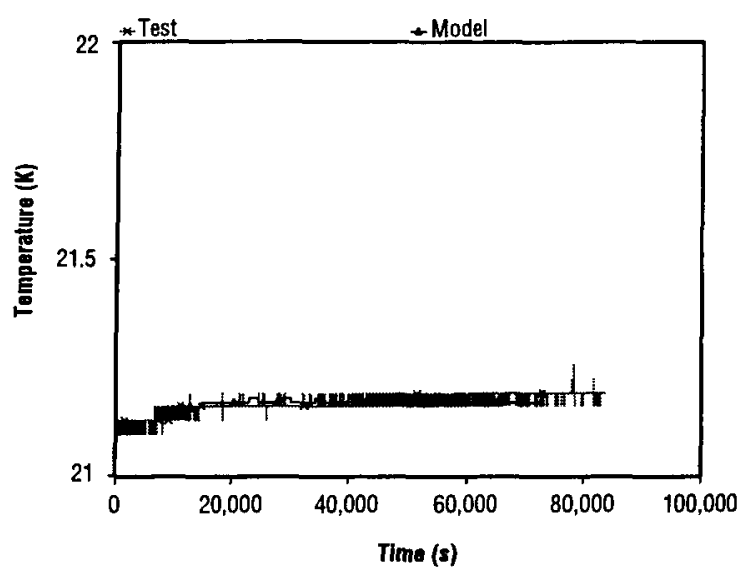

FIGURE 5. Bulk liquid saturation temperature, test P263968G. 


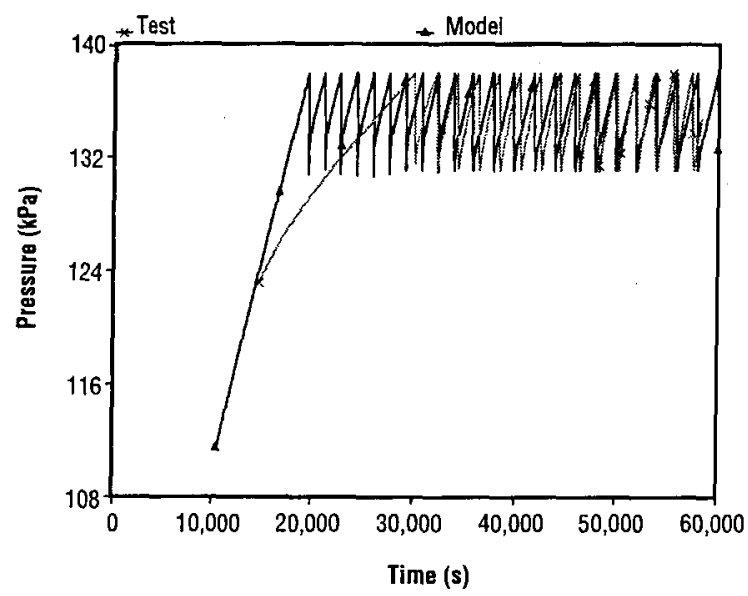

FIGURE 6. Ullage pressure, test P263981D.

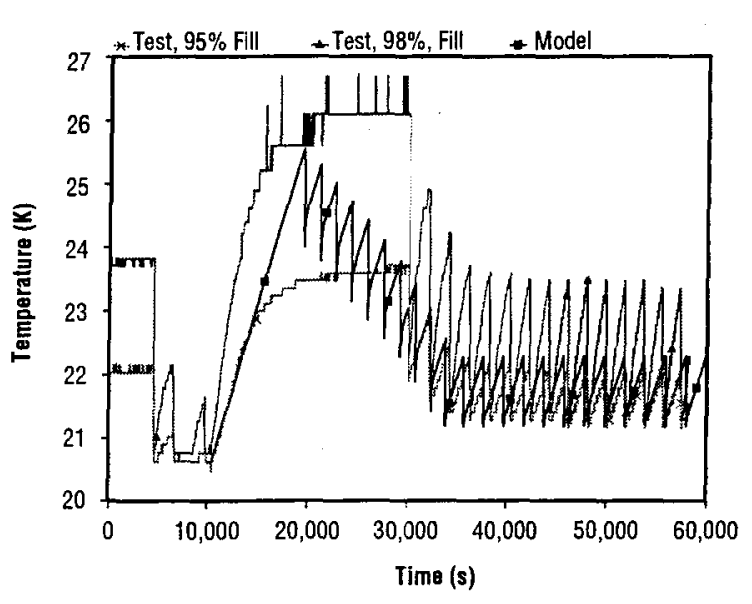

FIGURE 7. Ullage temperature, test P263981D.

temperatures and indicates that the average measured temperatures were slightly above the computed temperatures $(\approx 0.75 \mathrm{~K})$. The bulk liquid saturation pressure and temperature are shown in FIGS 8 and 9, respectively. The predicted bulk liquid pressures and temperatures are within $4 \mathrm{kPa}$ and $0.1 \mathrm{~K}$ of the measured values, respectively.

\section{Test Segment P263981X - High Heat Leak and GHe Pressurant Effects, 50\% Fill Level}

Correlations for self-pressurization, mixing, and venting were performed using test segment P263981X and with GHe injected intoullage, with a 50\% fill level and 51-W heat leak. The injected GHe initially elevated the ullage pressure to above the upper control limit of $213 \mathrm{kPa}$ and then was vented to the lower control limit of $206.84 \mathrm{kPa}$, whereupon the tank was locked up and the testing began. After the tank self-pressurized to $213 \mathrm{kPa}$, the mixer started and decreased the ullage pressure to $\approx 211 \mathrm{kPa}$, where the pressure leveled off and began to rise. The vent was then manually cycled on and the ullage pressure decreased to the lower limit $(206.8 \mathrm{kPa})$. The sequence was repeated for two more cycles before testing was terminated. It is believed that the helium acted as a barrier to mass transfer and condensation

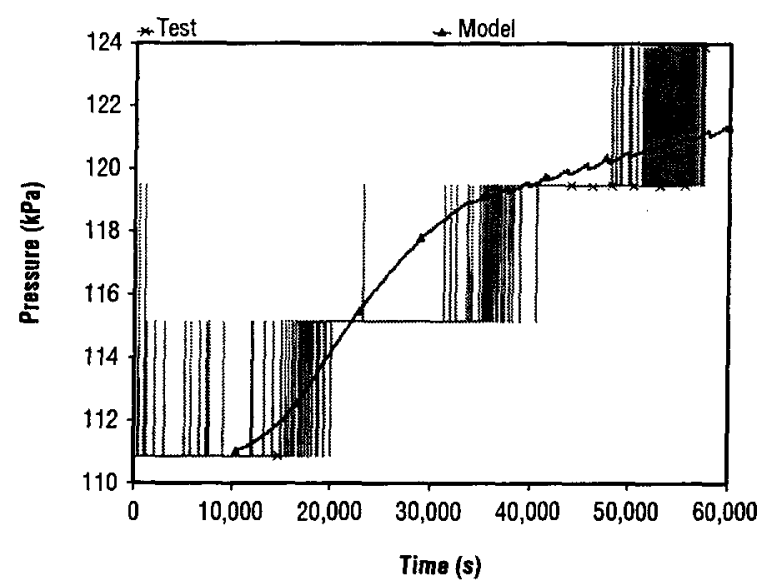

FIGURE 8. Bulk liquid saturation pressure, test P263981D.

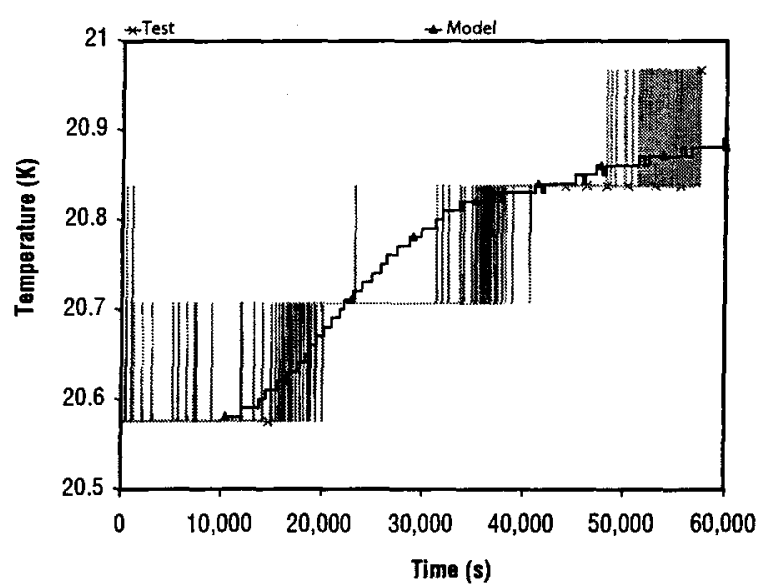

FIGURE 9. Bulk liquid saturation temperature, test P263981D. 
on the liquid surface, thereby constraining the effectiveness of the "mixing only" phase and necessitating use of the $\mathrm{J}-\mathrm{T}$ valve venting to further cool the ullage and reduce the pressure to the lower set point pressure.

The analytical and test ullage pressure comparison is presented in FIG 10. The $\mathrm{GH}_{2}$ and GHe partial pressures used in the model were 165.5 and $41.4 \mathrm{kPa}$, respectively. The model cycle rate was slightly faster than the test data reflected, primarily because the model did not reflect the "leveling off" effect observed in the "mixer only" testing. Also, since the analytical bulk liquid conditions never indicated saturation, venting did not occur with the model. The comparison of ullage temperature modeling with the test data is presented in FIG 11. The average model and test ullage temperatures were about 22.6 and $23 \mathrm{~K}$, respectively; i.e., were within $0.4 \mathrm{~K}$. The bulk liquid saturation pressure and temperature correlations are presented in FIGS 12 and 13, respectively. The model indicated that the saturation pressure and temperature continued to rise throughout the test segment, whereas the measured saturation conditions remained relatively constant. Longer duration testing is definitely required to better define and analytically correlate the effects of helium pressurant on TVS operation and long-term trends.

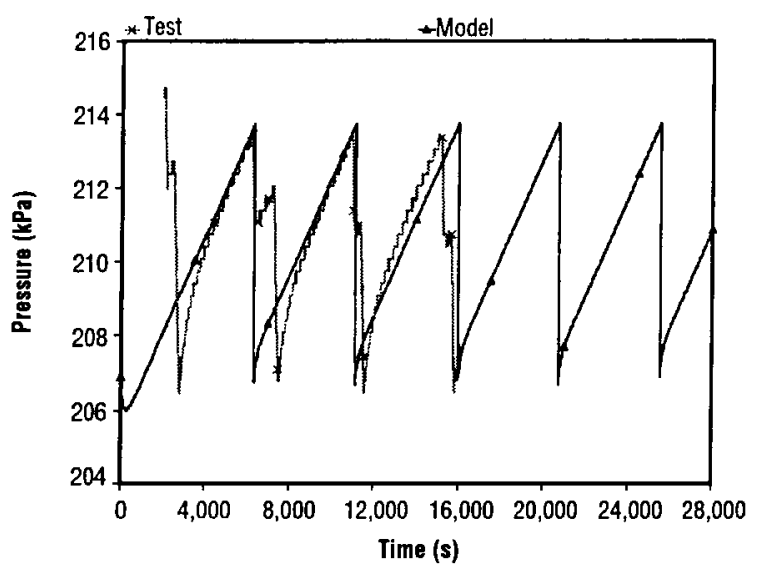

FIGURE 10. Ullage pressure, test P263981X.

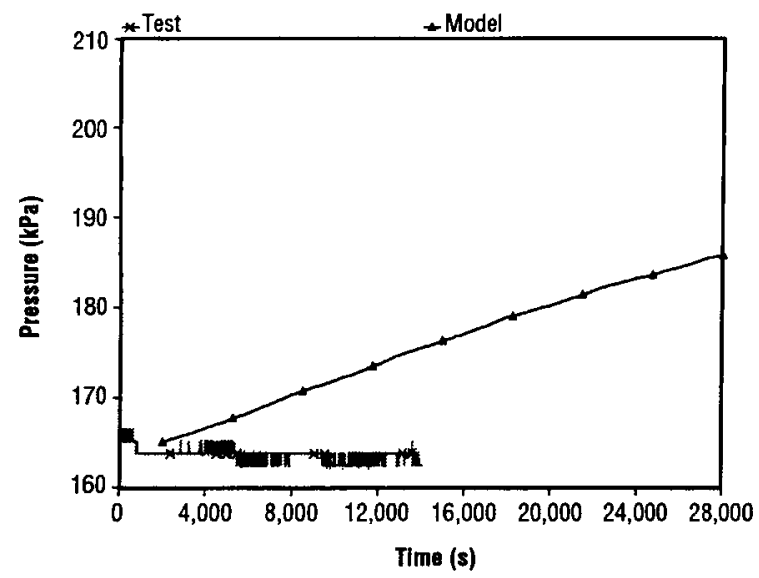

FIGURE 12. Bulk liquid saturation pressure, test P263981X.

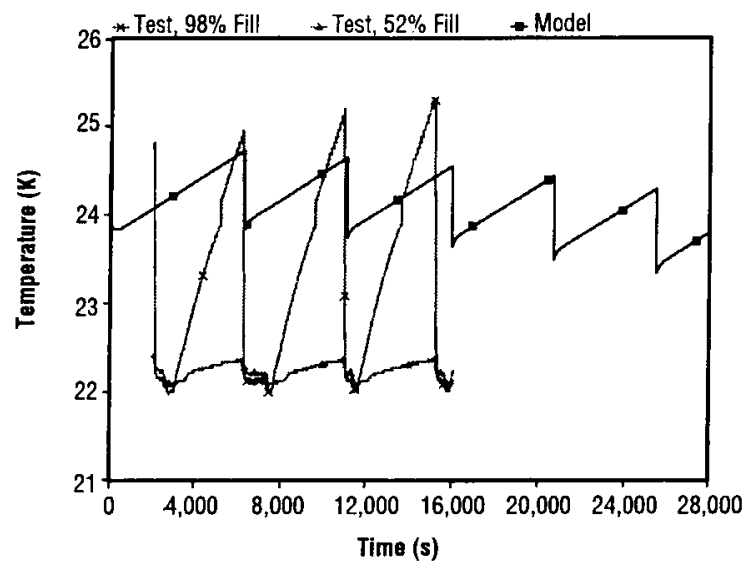

FIGURE 11. Ullage temperature, test P263981X.

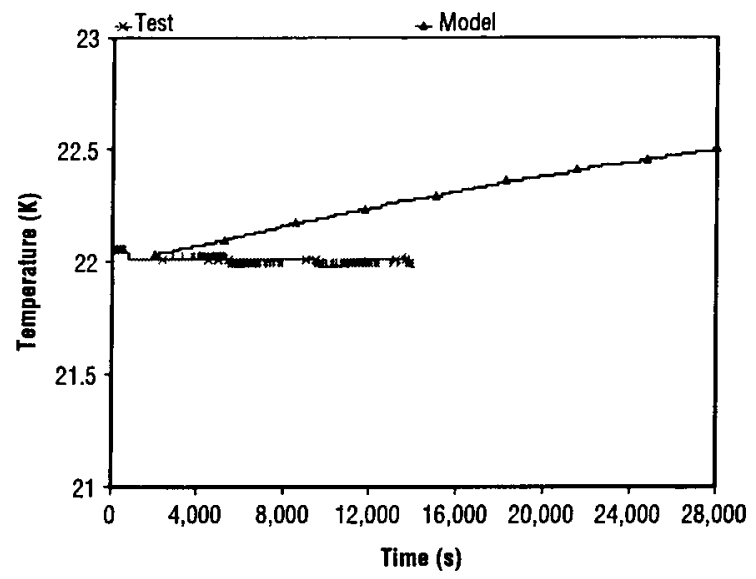

FIGURE 13. Bulk liquid saturation temperature, test P263981X. 


\section{SUMMARY}

Using the transient one-dimensional code formulated to characterize the MHTB TVS performance, correlations with the measured ullage pressure and temperature and the bulk liquid saturation pressure and temperature were performed for seven representative test segments. Correlations for the extended self-pressurization periods after each tank lockup indicated that the model pressure rise rates exceeded measured values. It is believed that the analytical modeling, which assumes that the liquid and ullage are each represented by single nodes, did not accurately simulate the complex energy exchange that actually occurred at the liquid-vapor interface. In the model, the thermal energy addition to the ullage is assumed to be at a constant rate, whereas in reality, a low-temperature mass transfer across the liquidvapor interface could suppress the ullage pressure rise rate.

Once the mixing and venting cycles began, analytical predictions and measured data more closely matched. With the low heat leak condition, it was noted that the measured pressure rise rates were slightly greater than analytically modeled, whereas the pressure reduction rates were practically identical. The model cycle rates ranged from $11 \%$ to $33 \%$ lower than measured. However, the cycle rate correlations improved with the higher heat leak condition; the measured rates were within $4 \%$ to $14 \%$ for without-venting modes and almost identical for with-venting modes. The correlations for ullage pressure and temperature and bulk liquid saturation pressure and temperature indicated relatively good agreement for the entire range of conditions tested.

Limited testing was conducted to evaluate TVS performance with helium in the ullage. During destratification testing, the J-T vent valve had to be manually opened to achieve the lower set point ullage pressure even though the bulk liquid was not saturated. Since the bulk liquid was not saturated, the analytical model did not indicate venting. It was concluded that helium constrained the energy exchange between $\mathrm{GH}_{2}$ and $\mathrm{LH}_{2}$, reducing the condensation effects of both the sprayed droplets and convection at the bulk liquid-vapor interface. Further testing is required to ascertain the long-term effects of helium on TVS performance.

\section{ACKNOWLEDGMENTS}

The authors extend appreciation to Kevin Pedersen and the test team at test stand 300 for their dedication to performing the testing. Special thanks also is given to Jim Martin and Leslie Curtis, and to Tibor Lak and Han Nguyen of the Boeing Company.

\section{REFERENCES}

1. Lak, T., and Wood, C., "Zero-G Thermodynamic Venting System Final Report," Rockwell Aerospace, Downey Operations, Report No. SSD 94M0038, Contract Number NAS8-39202, 1994.

2. Martin, J., and Hastings, L., "Large-Scale Liquid Hydrogen Testing of a Variable Density Multilayer Insulation With a Foam Substrate," NASA TM-2001-211089, Marshall Space Flight Center, AL, June 2001.

3. Flachbart, R.H., Hastings, L.J., and Martin, J.J., "Testing of a Spray Bar Zero Gravity Cryogenic Vent System for Upper Stages," Paper No. AIAA-99-2175, presented at the 35th AIAA/ASME/SAE/ ASEE Joint Propulsion Conference and Exhibit, Los Angeles, CA, June 20-24, 1999.

4. Nguyen, H., "Zero-G Thermodynamic Venting System (TVS) Performance Prediction Program," Rockwell Aerospace, Downey Operations, Contract NAS8-39202, May 24, 1994. 